\title{
SOCIO-ECONOMIC VULNERABILITY TO URBAN HEAT IN PHOENIX, ARIZONA AND DALLAS, TEXAS DURING JUNE 2020
}

\author{
T. Moss ${ }^{1}$, B. $\operatorname{Kar}^{2, *}$ \\ ${ }^{1}$ Brandeis University, 02453 Waltham, Massachusetts, USA (tmoss@ brandeis.edu) \\ ${ }^{2}$ Remote Sensing Group, Oak Ridge National Laboratory, 37830 Oak Ridge, Tennessee, USA (karb@ornl.gov)
}

Commission IV

KEY WORDS: Urban Heat Island, Socio-Economic Vulnerability, Land Surface Temperature, Landsat 8, Remote Sensing

\begin{abstract}
:
Urban expansion compounded by climate change appears to exacerbate the temperature difference between urban and rural areas. This temperature difference, known as the urban heat island (UHI) effect, results from lack of vegetation, increased impervious surfaces, excess heat released from human activities, and changing radiation and wind dynamics due to urban morphology. UHI has been found to increase heat-related illnesses, and in some instances, mortalities among vulnerable populations. Heat exposure is particularly pertinent in 2020, as stay-at-home orders and higher unemployment rates due to the COVID-19 pandemic have further exposed urban residents to local temperatures. Certain socio-economic groups that are more affected by COVID-19 are disproportionately exposed to high urban temperatures. We investigated the relationships between urban heat island intensity (UHII), normalized difference vegetation index (NDVI), and selected socio-economic factors for Dallas, TX and Phoenix, AZ for June 2020. We used an equalweighting approach to combine socio-economic factors obtained from 2018 US Census Bureau data to determine socio-economic vulnerability, and used Landsat 8 imagery to derive NDVI and land surface temperature. Pearson's correlation, hot spot analysis, and Moran's I tests revealed that socio-economic vulnerability was higher in areas with high urban temperatures and decreased vegetation.
\end{abstract}

\section{INTRODUCTION}

As cities expand, they exhibit stronger urban heat island (UHI) effects. UHI is the phenomenon where an urban area is significantly warmer than the surrounding rural areas due to lack of vegetation, increase in impervious surfaces, excess heat released from human activities, and changing radiation and wind dynamics due to urban morphology (Oke, 1982). The resulting temperature difference can be as high as $11^{\circ}$ Celsius (Glutting, 2013). Previous studies have concluded that higher urban temperatures have detrimental impacts on public health as they increase heat-related illness rates (Paravantis et al., 2017) (Voelkel et al., 2018).

Extreme heat, defined as the number of days when the temperature is above $35^{\circ} \mathrm{C}$ (Jones et al., 2015), exacerbates UHI and severely impacts the U.S. Sun Belt region, which spans much of the southern and western United States. This region is home to many of the fastest growing metropolitan areas in the country and has experienced considerable population growth since the 1970s due to immigration and the expansion of oil and defense industries (Briney, 2019). The Sun Belt is also a hot spot for COVID-19 infections. Of the 15 large metropolitan areas with the fastest doubling rate of COVID-19 cases in June 2020, 13 were in the Sun Belt (Olin, 2020).

Recent studies have revealed that specific demographic groups are more vulnerable to COVID-19 as well as to heat-related illnesses due to underlying health conditions, increased exposure due to unemployment, and lack of resources to adapt accordingly (Huang and Cadenasso, 2011; Oppel et al., 2020). Studies by Huan et al. (2011) and O'Neill and Ebi (2009) have found that higher temperatures correspond with areas that have high percentages of populations with low income, high poverty, lower educational levels, ethnic minorities, and elderly people. Black and Hispanic populations are almost three times as likely to be affected by COVID-19 than white populations (Oppel et al., 2020), and older adults have the highest risks of severe illness from the virus (CDC, 2020). Unemployed and retired populations are more likely to spend time in their homes than working populations, so they have greater potential exposure to the local temperatures around their homes. During 2020, stay-athome orders, school closures, remote work, and high unemployment rates kept additional people home. Lowerincome populations who live in rented homes are less likely to have access to air-conditioning or the means to pay for high electricity bills from increased electricity use for cooling. This poses a public health concern. This study explores the spatial relationships between socio-economic vulnerabilities and exposure to higher urban temperatures for Dallas-Fort Worth, TX, and Phoenix, AZ during June 2020.

\section{STUDY AREA AND DATA COLLECTION}

\subsection{Study Area}

We selected Dallas, TX, and Phoenix, AZ, for this study as these cities are in the Sun Belt (Figure 1). Dallas and Phoenix have high population density, experienced significant population growth from 2010 to 2017 (Table 1), and had high COVID-19 infection rates in 2020. On June 18, 2020, there were 378 positive COVID-19 cases per 100,000 people in Dallas-Fort Worth, TX and 495 positive COVID-19 cases per 100,000 people in the Phoenix, AZ area (Olin, 2020).

\footnotetext{
* Corresponding author
} 


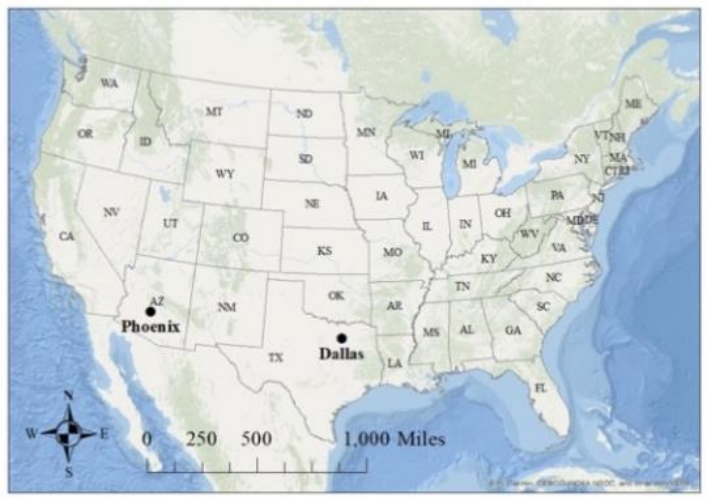

Figure 1. Map of cities studied

\begin{tabular}{|l|l|l|}
\hline City & $\begin{array}{l}\text { Dallas/ } \\
\text { Fort Worth }\end{array}$ & $\begin{array}{l}\text { Phoenix/Mesa/ } \\
\text { Scottsdale/Tempe }\end{array}$ \\
\hline County/Counties & $\begin{array}{l}\text { Dallas, } \\
\text { Tarrant }\end{array}$ & Maricopa \\
\hline State & TX & AZ \\
\hline 2010 Population & 226876 & 161719 \\
\hline $\begin{array}{l}\text { Population Density } \\
\text { (people/km } \text { ( }^{\text {) }}\end{array}$ & 1076.068 & 1080.213 \\
\hline $\begin{array}{l}\text { Pop. Change } \\
\text { (2010-2017) }\end{array}$ & 973431 & 544141 \\
\hline Climate Zone & Hot-Humid & Hot-Dry \\
\hline
\end{tabular}

Table 1. Cities in study

\subsection{Data}

We used Landsat imagery and socio-economic (SE) data from the U.S. Census Bureau for the two study sites. The data sets, their sources, and spatio-temporal resolutions are presented in Table 2. All data sets were converted to the World Geodetic System (WGS) 1984 Web Mercator (auxiliary sphere) spatial reference system. We implemented a model to create raster layers for $\mathrm{SE}$ variables at $10 \mathrm{~m} \times 10 \mathrm{~m}$ resolution, and retained the $30 \mathrm{~m} \times 30 \mathrm{~m}$ resolution for Landsat imagery.

\begin{tabular}{|l|l|l|l|}
\hline Data & LST & \multicolumn{2}{|l|}{ Socio-economic } \\
\hline $\begin{array}{l}\text { Specific } \\
\text { Data }\end{array}$ & $\begin{array}{l}\text { Landsat } \\
\text { OLI/TIRS } \\
\text { Band 4, Band } \\
\text { 5, Band 10 }\end{array}$ & Population & $\begin{array}{l}\text { Population, } \\
\text { age, housing } \\
\text { tenure, } \\
\text { employment, } \\
\text { income, race }\end{array}$ \\
\hline $\begin{array}{l}\text { Spatial } \\
\text { Resolution }\end{array}$ & $30 \mathrm{~m}$ & $\begin{array}{l}\text { Census } \\
\text { block }\end{array}$ & $\begin{array}{l}\text { Census tract, } \\
\text { block group }\end{array}$ \\
\hline $\begin{array}{l}\text { Temporal } \\
\text { Resolution }\end{array}$ & 16 day & Year & Year \\
\hline Time & $\begin{array}{l}\text { Image } \\
\text { dependent }\end{array}$ & 2010 & 2018 \\
\hline Source & $\begin{array}{l}\text { USGS } \\
\text { EarthExplorer }\end{array}$ & $\begin{array}{l}\text { U.S. } \\
\text { Census }\end{array}$ & $\begin{array}{l}\text { American } \\
\text { Community } \\
\text { Survey 5-Year } \\
\text { Estimates }\end{array}$ \\
\hline
\end{tabular}

Table 2. Data sets, sources, and resolution

2.2.1 Landsat Data: We used Landsat 8 OLI/TIRS data to derive land surface temperature (LST) and normalized difference vegetation index (NDVI) for each city. LST is used to calculate the urban heat island intensity (UHII) and NDVI provides information about the presence of vegetation. We selected imagery for June 2020 with minimal cloud cover (Table 3). We used Band 10 (thermal infrared) to calculate LST, and Band 4 (red) and Band 5 (near infrared) to calculate NDVI.

\begin{tabular}{|l|l|l|l|}
\hline City & Image Path & Image Row & Date \\
\hline Dallas, TX & 27 & 37 & July 17, 2020 \\
\hline Phoenix, AZ & 37 & 36 & June 30, 2020 \\
\cline { 2 - 4 } & 37 & 37 & June 21, 2020 \\
\cline { 2 - 4 } & 36 & 37 & June 21, 2020 \\
\hline
\end{tabular}

Table 3. Landsat 8 OLI/TIRS images used in study

2.2.1 U.S. Census Bureau Data: We used the latest (2018) American Community Survey 5-Year Estimates data at the census block group or census tract level, for population, age, race, housing tenure, employment status, and household income variables. We used 2010 population at the census block level to disaggregate and redistribute the 2018 socio-economic data at the block level.

\section{METHODOLOGY}

\subsection{Landsat Data Processing}

Although Landsat 8 has two thermal bands (10 and 11), band 11 is not recommended for LST calculation (Xu, 2015). So, we implemented the following steps to calculate LST using Band 10 (Figure 2). We used equations 1 and 2 to convert digital numbers (DN) to radiance and then to Kelvin, respectively. We obtained corresponding constants for the equations from the Landsat 8 Data Users Handbook (Zanter, 2019). Finally, we converted the temperature from Kelvin to degree Fahrenheit using equation 3. For cities with multiple images, we mosaicked the LST layers into a single raster. We used zonal statistics to determine the maximum LST in each urban area and per block for each city. We calculated the UHI intensity (UHII) per block by subtracting the maximum LST per block from the maximum LST of each urban area, using boundaries from the U.S. Census Bureau. Lower UHII values correspond to higher temperatures.

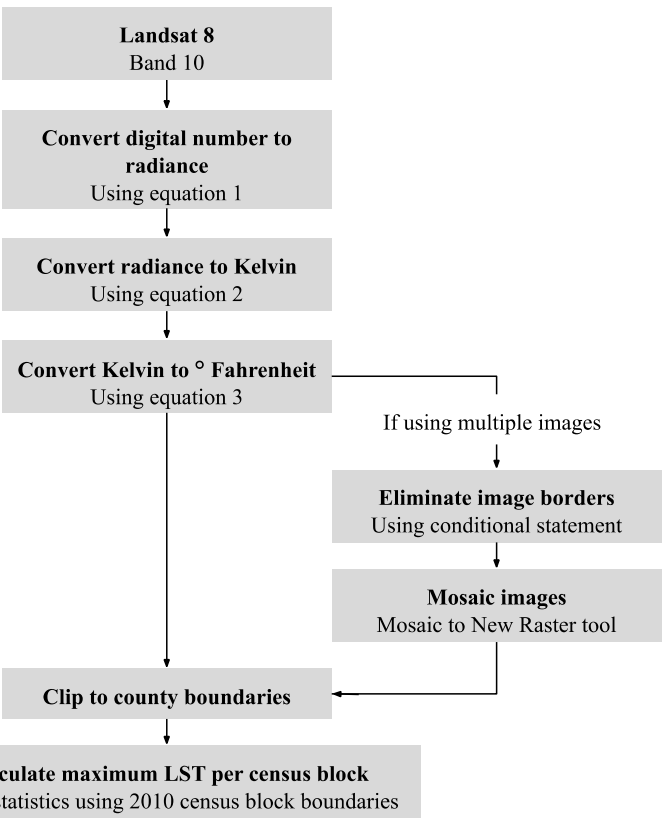

Figure 2. Processing steps for LST calculation

$$
L_{\lambda}=M_{L} * Q c a l+A_{L}
$$


where

$$
\begin{array}{ll}
\mathrm{L}_{\lambda} & =\text { Spectral radiance }(\mathrm{W} /(\mathrm{m} 2 * \mathrm{sr} * \mu \mathrm{m})) \\
\mathrm{M}_{\mathrm{L}} & =\text { Radiance multiplicative scaling factor } \\
& =0.00033420 \text { for Landsat } 8 \text { Band } 10 \\
\mathrm{~A}_{\mathrm{L}} & =\text { Radiance additive scaling factor } \\
& =0.1 \text { for Landsat } 8 \text { Band } 10 \\
\text { Qcal } & =\text { Level } 1 \text { pixel value DN }
\end{array}
$$

$$
T=\frac{K 2}{\ln \left(\frac{K 1}{L \lambda}+1\right)}
$$

where

$\mathrm{T}=$ Effective at-satellite temperature in Kelvin

K2 = Calibration constant 2

$=1321.0789$ Kelvin for Landsat 8 Band 10

$=$ Calibration constant 1

$=607.75\left(\right.$ Watts $/\left(\mathrm{m}^{2} * \mathrm{sr} * \mu \mathrm{m}\right)$ for Landsat 5

$=666.09\left(\right.$ Watts $/\left(\mathrm{m}^{2} * \mathrm{sr}^{*} \mu \mathrm{m}\right)$ for Landsat

$7 \mathrm{ETM}+=774.8853$ for Landsat 8 Band 10

$T f=(T-273) * 1.8+32$

where

$$
\mathrm{T}=\mathrm{LST} \text { in degrees Fahrenheit }
$$

To calculate NDVI, we first converted DN values for band 4 (red) and band 5 (NIR) to reflectance values using equation 4 , and corrected for the sun angle using equation 5. We then calculated NDVI using equation 6. Constants and equations were taken from the manuscript by D'Allestro and Claudio (2015) and from Landsat image metadata files (D'Allestro and Claudio, 2015). We eliminated image borders and mosaicked NDVI layers as needed. We nullified the few NDVI values that were beyond the -1.0 to 1.0 range due to overcorrection from the satellite's atmospheric correction algorithm. Finally, we used zonal statistics to obtain mean NDVI values by block.

$$
\rho \lambda^{\prime}=M \rho * Q c a l+A \rho
$$

where

$$
\begin{array}{ll}
\rho \lambda & =\text { top of atmosphere (TOA) planetary } \\
& \text { reflectance without correction for solar } \\
& \text { angle } \\
& =\text { Band-specific multiplicative rescaling } \\
\text { factor from image metadata } & \\
\text { A } \rho \quad \text { Band-specific additive rescaling factor } \\
\text { Qcal } & =\text { Quantized and calibrated standard product } \\
& \text { pixel value (digital number) }
\end{array}
$$

$$
\rho \lambda=\rho \lambda{ }^{\prime} / \sin \theta S E
$$

where

$$
\begin{aligned}
\rho \lambda & =\text { TOA planetary reflectance } \\
\theta \mathrm{SE} & =\text { Local sun elevation angle from image } \\
& \text { metadata } \\
N D V I= & \frac{N I R-\text { red }}{\text { NIR }+ \text { red }}=\frac{\text { band } 5 \rho \lambda-\text { band } 4 \rho \lambda}{\text { band } 5 \rho \lambda+\rho \lambda}
\end{aligned}
$$

\subsection{Dasymetric Mapping of Socio-Economic Variables}

We used a dasymetric mapping areal interpolation approach to dis-aggregate the SE data to the 2010 block boundaries (Figure 3 ). First, we created a binary raster layer using 2010 block boundaries and population by block, such that blocks with population were assigned a value of 1 . Next, we created density rasters for each SE variable (Figure 4), which we then multiplied by the block binary to determine the total count for each SE variable at the block level. Finally, we calculated the percent of each SE variable per block. For age and race variables, we calculated the percent out of the total 2018 population per block. For income, we calculated the percent of households with annual income less than $\$ 25,000$. For rented homes, we calculated the percent out of the total housing units per block, and for unemployment we calculate the percent out of the total civilian labor force per block.

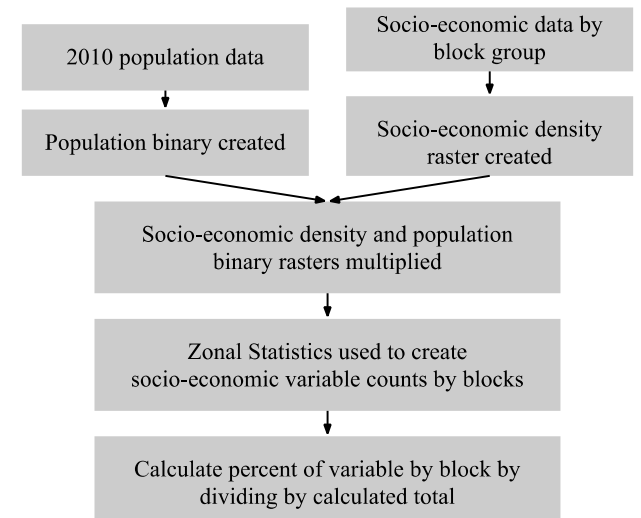

Figure 3. Dasymetric approach for mapping percent of socioeconomic variables

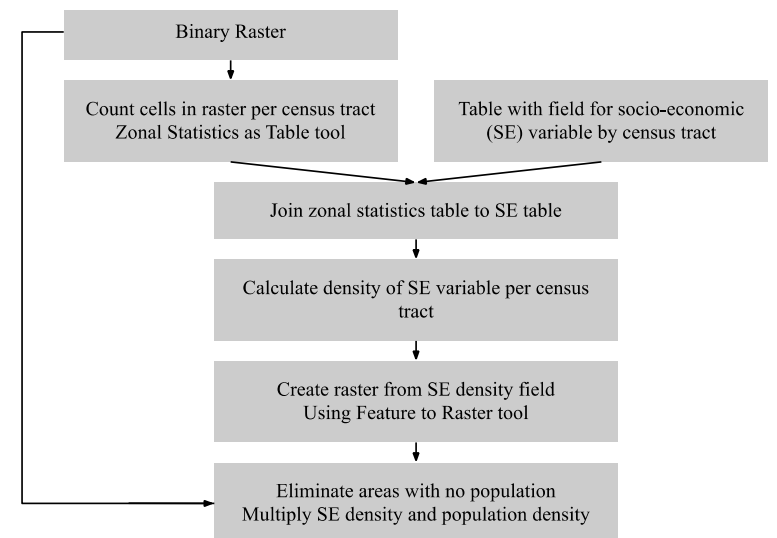

Figure 4. Steps to create density rasters for socio-economic variables

\subsection{Creating Stacked Socio-Economic Vulnerability Maps}

For each SE variable, we first selected blocks where the variable percent was greater than zero. We then rasterized the remaining data. We reclassified the percent of each SE variable (aged 0-14, aged 60 and up, Black, Hispanic, rented homes, income less than $\$ 25,000$, and percent unemployed) using Jenks Natural Breaks classification into five classes. The first class represented least vulnerable (assigned a value of 1) and the last class represented most vulnerable (assigned a value of 5). We then combined SE variables using an equal weighting approach to generate SE vulnerabilities. Finally, we determined the SE vulnerability score per block using zonal statistics (majority).

Natural Breaks classification reduces variance within each class, so that the similarity between values in a class is maximized. Natural Breaks classification accounts well for skewed data and allows for small bin ranges when suitable, as opposed to Equal Interval, Quantile, or Geometric Interval methods. Because SE variables were positively skewed, we used Jenks Natural Break classification. We did not use a defined interval for both cities, 
as we wanted to calculate the relative vulnerability per city, not absolute vulnerability across the Sun Belt. Appendix A shows the Natural Breaks classification for each variable.

\subsection{Statistical Analysis}

We used hot spot analysis (Getis-Ord Gi*) to visualize statistically significant areas with high and low values of the variables. Before performing the remaining statistical analysis, we eliminated all blocks with zero population and zero LST. We used GeoDa software to run Bivariate Local Moran's I spatial autocorrelation tests to study significant spatial relationships between the variables. Pearson's correlation and scatterplots were used to find absolute relationships between variables, disregarding spatial relationships. We multiplied the LST and NDVI raster layers by a binary to mask out waterbodies before calculating correlation coefficients between LST and NDVI.

\section{RESULTS AND DISCUSSION}

\subsection{Land Surface Temperature, Urban Heat Island Index, and Normalized Difference Vegetation Index}

The LST ranges shown are likely higher than the air temperature ranges, as LST accounts for solar radiation absorbed by impervious surfaces. Although air temperature and relative humidity better indicate human experience of UHI, these parameters were not used in the current phase of this study. Maps of reclassified UHII using Jenks Natural Breaks classification are included, which show the intraurban temperature differences as well as temperature gradients in Phoenix and Dallas. The UHII and LST maps shown here are almost identical, as expected. NDVI provides information about the location and health of plants. In the NDVI images, darker green areas indicate healthy and abundant vegetation, dark purple indicates water, and areas in lighter purple indicate impervious surfaces or desert, in the case of Phoenix. Evidently, NDVI distribution in the cities follows the LST distribution, which is expected. Hot spot analysis results, which represent clusters of high and low values, accompany selected LST and NDVI distributions. Dark red indicates hot spots with $99 \%$ confidence and dark blue indicates cold spots with $99 \%$ confidence.

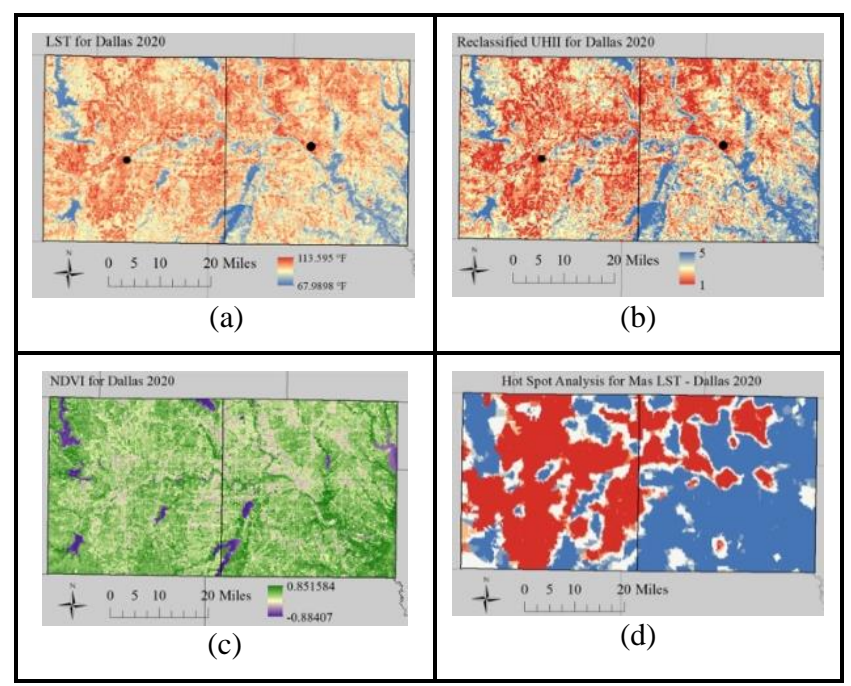

Figure 5. LST (a), UHII (b), NDVI (c), and LST hot spots (d) maps for Tarrant and Dallas Counties, TX for June 2020.

The left box in each map in Figure 5 represents Tarrant County, with the center of Fort Worth indicated by the left point in
Figures 6a and 6b. The right box represents Dallas County, with the center of Dallas indicated by the right point in Figures $6 \mathrm{a}$ and 6b. The UHII and LST maps (Figures 6a and 6b) illustrate that temperature increases with proximity to the downtown areas of Fort Worth and Dallas. The Fort Worth area has a larger area with higher temperature than the Dallas area has.

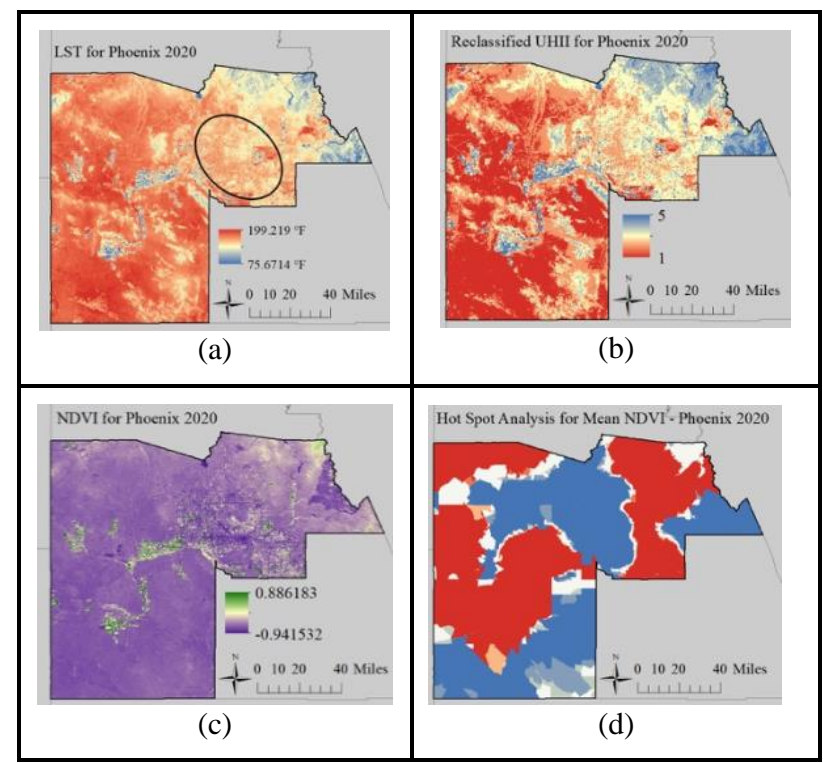

Figure 6. LST (a), UHII (b), NDVI (c), and NDVI hot spots (d) maps for Maricopa County, AZ for June, 2020

The metropolitan Phoenix/Scottsdale/Tempe/Mesa falls in the oval shown in the LST map (6a). The cooler areas portrayed in blue in Figures $6 \mathrm{a}$ and $6 \mathrm{~b}$ represent the Superstition Mountains northeast of Phoenix, and the red areas south and west of Phoenix largely correspond to the Sonoran Desert. Phoenix exhibits a reverse UHI effect, where the urbanized areas tend to be cooler than the surrounding desert. This may be due to the urban vegetation added to the urban area, as can be seen in the NDVI maps (Figures $6 \mathrm{c}$ and $6 \mathrm{~d}$ ). The dark green areas shown in the western part of the NDVI map for Maricopa County (Figure 6c) represent farmland and can also be distinguished as cooler in the corresponding LST and UHII maps (Figures 6a and 6b).

\subsection{Socio-Economic Vulnerability Index}

Figures 7 and 8 represent the SE vulnerability for Dallas and Phoenix. Vulnerability in Dallas tends to increase with proximity to the urban centers, where the UHII is higher and NDVI is lower. A similar trend is present in Phoenix where the socio-economic vulnerability is higher in the urban center and western part of the county, as opposed to the surrounding areas. These trends illustrate that heat mitigation strategies in Dallas and Phoenix should target urban centers, as these areas have both the highest heat exposure and the most vulnerable populations.

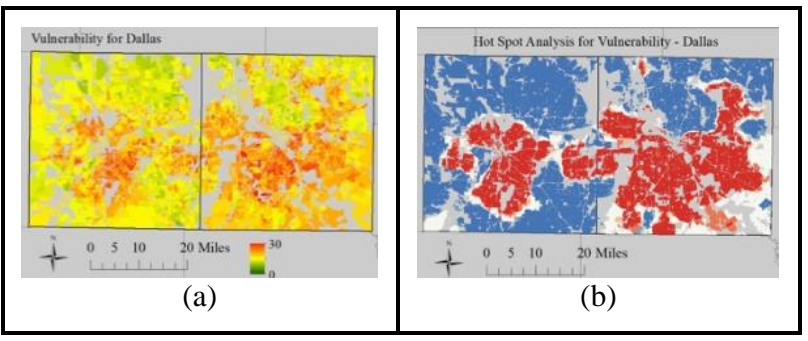

Figure 7. Socio-economic vulnerability map and hot spot analysis for Dallas and Tarrant Counties 2018. 


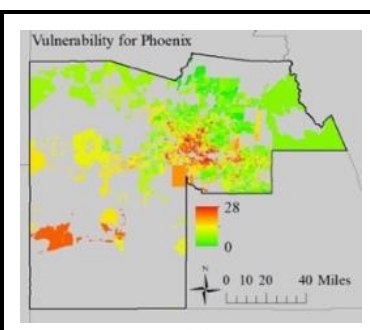

(a)

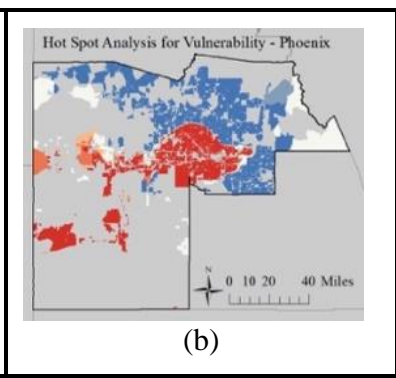

(b)
Figure 8. Socio-economic vulnerability map and hot spot analysis for Maricopa County 2018.

\subsection{Intraurban Spatial Variability}

Both UHII and vulnerability tend to increase with proximity to the urban centers. We determined proximity to urban center based on the distance of each block's centroid to the centroid of the corresponding urban boundary. Figures 9 and 10 show the mean UHII and mean distance from urban center for blocks in the top $25 \%$ of vulnerability for the two cities. For both Dallas and Phoenix, trend lines show that overall, as vulnerability increases, temperature increases and distance from urban center decreases.

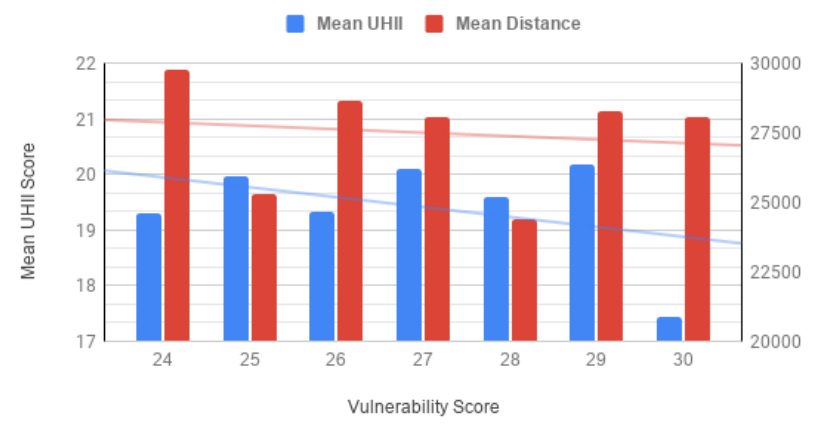

Figure 9 - Mean UHII and distance from Dallas's urban center for blocks with the top $25 \%$ of vulnerability scores.

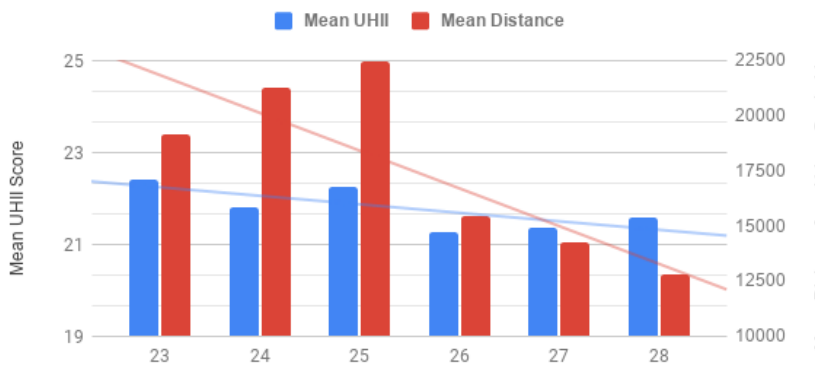

Vulnerability Score

Figure 10 - Mean UHII and distance from Phoenix's urban center for blocks with the top $25 \%$ of vulnerability scores.

\subsection{Statistical Analysis}

While the correlation coefficients for Dallas are not high, they are significant (Table 4). The scatter plots and coefficients indicate SE vulnerability is higher for areas with increased LST and reduced vegetation. As shown in Table 4, there is an inverse correlation between LST and UHII. There is a relatively strong negative relationship between LST and NDVI. Bivariate Moran's I spatial autocorrelation in Figure 12 indicates significant clusters of blocks where there are significant relationships between LST and vulnerability.

\begin{tabular}{|l|l|l|l|l|}
\hline & LST & UHII & NDVI & Vuln. \\
\hline Max LST & 1 & & & \\
\hline UHII & -1 & 1 & & \\
\hline Mean NDVI & -0.65 & 0.65 & 1 & \\
\hline Vulnerability & 0.03 & -0.03 & -0.05 & 1 \\
\hline
\end{tabular}

Table 4. Pearson correlation coefficients for Dallas.

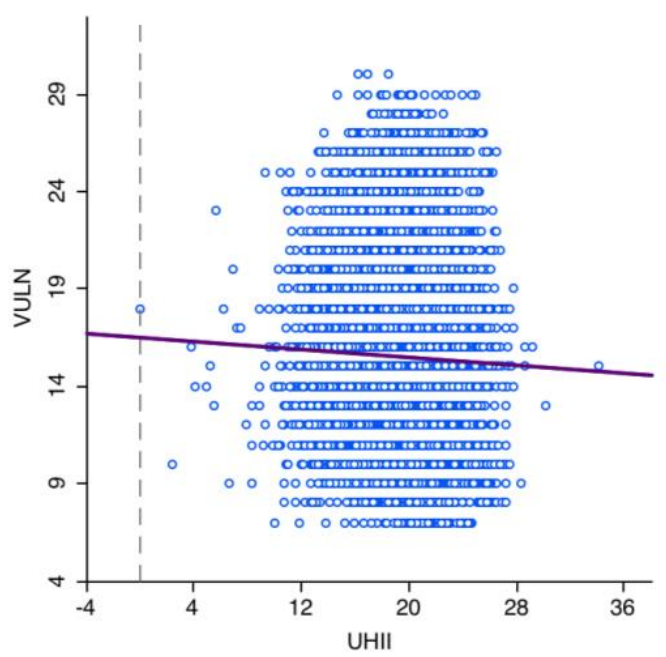

Figure 11. Scatterplot of maximum UHII versus vulnerability index for Dallas.

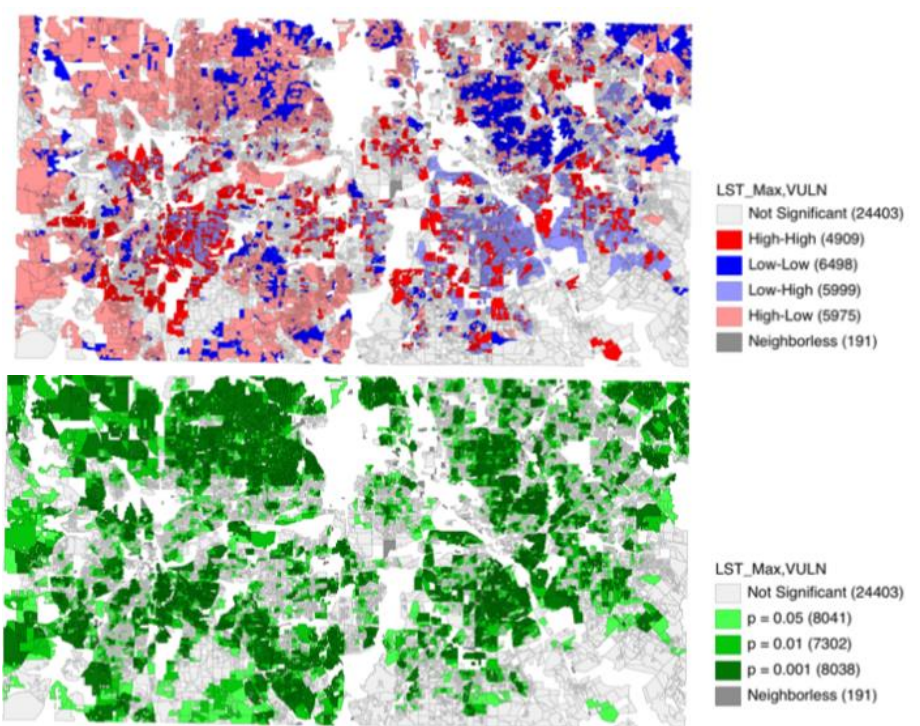

Figure 12. Bivariate Local Moran's I spatial autocorrelation cluster and significance maps for maximum LST versus socioeconomic vulnerability for Dallas.

A similar trend exists for Phoenix where the vulnerability increases with LST and reduced NDVI. However, the correlation coefficients between max LST, vulnerability and mean NDVI are stronger than the corresponding coefficients for Dallas. The relationship between LST and NDVI is still negative, but the strength of the relationship is weaker for Phoenix than for Dallas. 


\begin{tabular}{|l|l|l|l|l|}
\hline & LST & UHII & NDVI & Vuln. \\
\hline Max LST & 1 & & & \\
\hline UHII & -1 & 1 & & \\
\hline Mean NDVI & -0.34 & 0.34 & 1 & \\
\hline Vulnerability & 0.40 & -0.40 & -0.19 & 1 \\
\hline
\end{tabular}

Table 5. Pearson correlation coefficients for Phoenix.

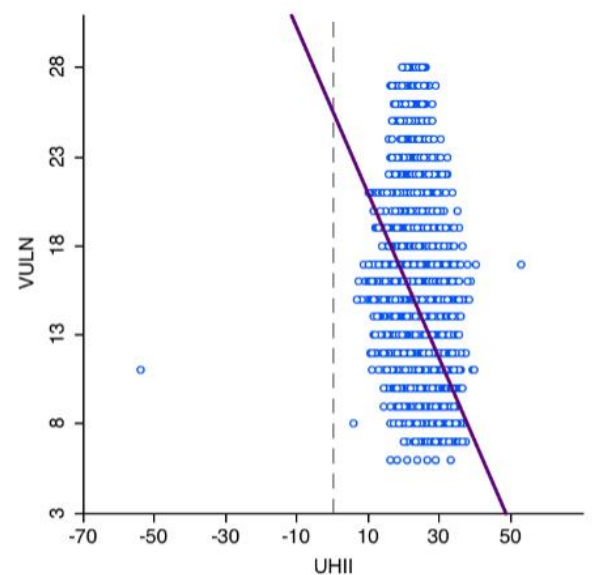

Figure 13. Scatterplot UHII versus vulnerability index for Phoenix. There is a negative UHII value because the hottest block in Maricopa County is not located inside the urban boundary.

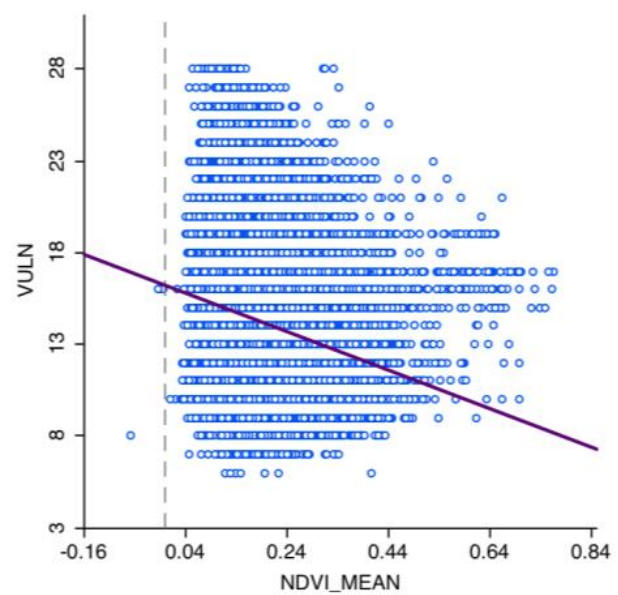

Figure 14 - Scatter plot for mean NDVI versus vulnerability index for Phoenix.

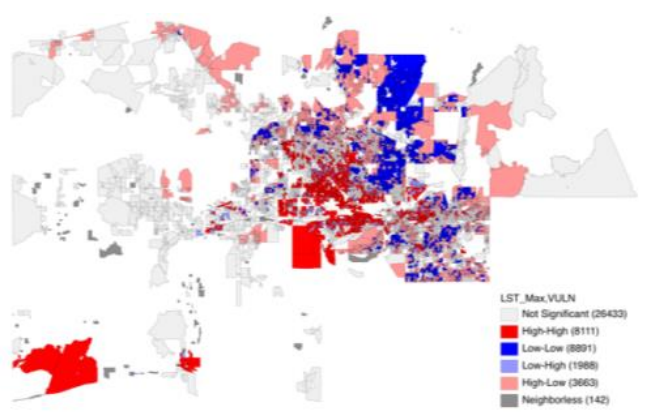

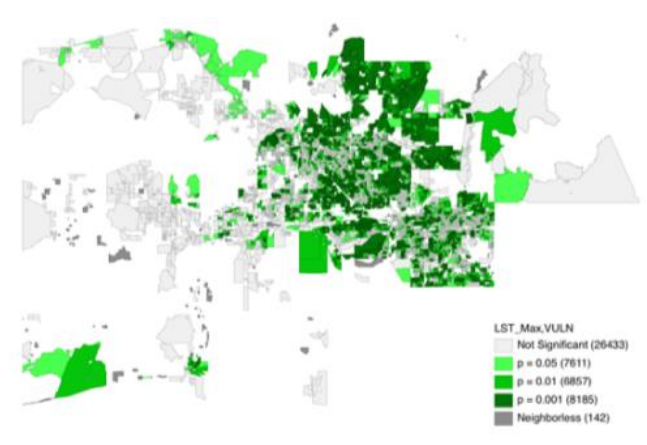

Figure 15 - Bivariate Local Moran's I spatial autocorrelation cluster and significance maps for maximum LST versus socioeconomic vulnerability for Phoenix.

The dark red and dark blue areas of the spatial autocorrelation map, indicating the relationship between high vulnerability and high LST and low vulnerability and low LST respectively, correspond to darker shades of green on the significant map. This indicates significant spatial relationships between vulnerability and heat exposure in Phoenix.

\section{CONCLUSION}

It is evident that socio-economic vulnerability is higher across the Sun Belt in areas with high temperature due to the UHI effect and reduced vegetation. Therefore, it could be concluded that the urban areas that are susceptible to UHI are occupied by vulnerable population groups in both Dallas-Fort Worth and Phoenix. The CDC also identifies that many of the socioeconomic groups with increased vulnerability to heat exposure (elderly, Hispanic, Black) are at higher risk of experiencing heatrelated illnesses as well as COVID-19 infections. Given that the number of COVID-19 infections is on the rise, from a public health perspective, it is essential to implement mitigation strategies including mobile healthcare facilities in the urban centers to reduce the adverse impacts of heat exposure and COVID-19 on the vulnerable populations.

Our study identified areas that are at high risk for heat-related illnesses based on socio-economic vulnerability and exposure to high temperatures due to UHI. Future analysis will incorporate other parameters, such as access to heat refuge, relative humidity, air temperature, pollution, mobility, number of COVID-19 infected cases, and mortalities in these cities to understand the implication of environmental factors and human activities on heat exposure and UHII. Future research will also be expanded to other metropolitan areas including Los Angeles and Atlanta (other epicenters of COVID-19) to assess if the relationship uncovered in this study applies to other metropolitan areas.

A major takeaway of this study is that the vulnerable populations are at a higher risk of experiencing heat related illnesses. These demographic groups have also been identified to be susceptible to COVID-19 infections. The study also revealed the spatial distribution of these vulnerable population groups, which could be used by city planners and public health professionals to undertake strategies, such as the deployment of green infrastructures, to reduce UHI effects. The results of this study could also be used to explore the accessibility of these demographic groups to healthcare, which can subsequently be helpful in identifying potential sites for mobile hospitals and to locate COVID-19 testing facilities and/or vaccination facilities once vaccines are available for public use. 


\section{ACKNOWLEDGEMENTS}

This work was supported in part by the U.S. Department of Energy, Office of Science, Office of Workforce Development for Teachers and Scientists (WDTS) under the Science Undergraduate Laboratory Internship program.

This manuscript has been authored by UT-Battelle, LLC under Contract No. DE-AC05- 00OR22725 with the U.S. Department of Energy. The U.S. Government retains and the publisher, by accepting the article for publication, acknowledges that the U.S. Government retains a non-exclusive, paid-up, irrevocable, world-wide license to publish or reproduce the published form of this manuscript, or allow others to do so, for United States Government purposes.

\section{REFERENCES}

Briney, A. 2019. "Do You Know the Location and What States Are in the Sunbelt Region?" ThoughtCo. Accessed June 21, 2019. https://www.thoughtco.com/sun-belt-in-united-states1435569 .

CDC. 2020: Older Adults and COVID-19. Centers for Disease Control and Prevention. https://www.cdc.gov/coronavirus/2019ncov/need-extra-precautions/older-adults.html.

D'Allestro, P., Claudio, P. 2015. GIS application for NDVI calculation using Landsat 8 OLI images. International Journal of Applied Engineering Research, 10(21), 42099-42102. Retrieved from https://www.academia.edu/21540430/GIS_application_for_ND VI_calculation_using_Landsat_8_OLI_images.

Fung, W. Y., Lam, K. S., Nichol, J., Wong, M. S. 2009 Derivation of Nighttime Urban Air Temperatures Using a Satellite Thermal Image. Journal of Applied Meteorology and Climatology, 48(4), 863-872. doi:10.1175/2008jamc2001.1

Glutting, J. 2013. Excess Heat-Related Mortality in MicroUrban Heat Islands: A Case-only Study in Barcelona. GI_Forum 2013 - Creating the GISociety, 137-146. doi:10.1553/giscience2013s 137

Huang, G., Zhou, W., Cadenasso, M. 2011. Is everyone hot in the city? Spatial pattern of land surface temperatures, land cover and neighborhood socioeconomic characteristics in Baltimore, MD. Journal of Environmental Management, 92(7), 1753-1759. doi:10.1016/j.jenvman.2011.02.006

Jones, B., O’Neill, B. C., Mcdaniel, L., Mcginnis, S., Mearns, L.O., Tebaldi. 2015. "Future Population Exposure to US Heat Extremes." Nature Climate Change 5, no. 7, 652-55. doi:10.1038/nclimate2631.

Oke, T. R. 1982. The energetic basis of the urban heat island. Quarterly Journal of the Royal Meteorological Society, 108(455), 1-24. doi:10.1002/qj.49710845502

Olin, Andy. 2020. COVID-19 Hot Spots Emerge across the Sun Belt as States Expand Reopenings, Rice Kinder Institute for Urban Research, kinder.rice.edu/urbanedge/2020/06/23/Coronavirus-hot-spotsemerge-across-sun-belt-states-expand-reopenings. Accessed 10 Aug. 2020.
O’Neill, M. S., Ebi, K. L. 2009. Temperature Extremes and Health: Impacts of Climate Variability and Change in the United States. Journal of Occupational and Environmental Medicine, 51(1), 13-25. doi:10.1097/jom.0b013e318173e122

Oppel, R., Gebeloff, R., Lai, K. K. R., Wright, W., \& Smith, M. 2020, July 5. The Fullest Look Yet at the Racial Inequity of Coronavirus. The New York Times. https://www.nytimes.com/interactive/2020/07/05/us/coronaviru s-latinos-african-americans-cdc-data.html.

Paravantis, J., Santamouris, M., Cartalis, C., Efthymiou, C., Kontoulis, N. 2017. Mortality Associated with High Ambient Temperatures, Heatwaves, and the Urban Heat Island in Athens, Greece. Sustainability, 9(4), 606. doi:10.3390/su9040606

Voelkel, J., Hellman, D., Sakuma, R., Shandas, V. 2018. Assessing Vulnerability to Urban Heat: A Study of Disproportionate Heat Exposure and Access to Refuge by SocioDemographic Status in Portland, Oregon. International Journal of Environmental Research and Public Health, 15(4), 640. doi:10.3390/ijerph15040640

Xu, Hanqiu. 2015. Retrieval of the reflectance and land surface temperature of the newly-launched Landsat 8 satellite. Chinese Journal of Geophysics- Chinese Edition. 58. 741-747. doi:10.6038/cjg20150304.

Zanter, K. 2019. Landsat 8 Data Users Handbook (U.S. Geological Survey) [Version 4.0]. Department of the Interior.

\section{APPENDIX}

\section{Natural Breaks Classification Values for SE Percents}

\begin{tabular}{|l|l|}
\hline $\begin{array}{l}\text { 1) Income } \\
\text { Dallas 2018 }\end{array}$ \\
\hline Percent range & $\begin{array}{l}\text { New } \\
\text { Value }\end{array}$ \\
\hline $0.56-9.46$ & 1 \\
\hline $9.46-18.10$ & 2 \\
\hline $18.10-28.32$ & 3 \\
\hline $28.32-41.15$ & 4 \\
\hline $41.15-67.61$ & 5 \\
\hline
\end{tabular}

\begin{tabular}{|l|l|}
\hline \multicolumn{2}{|l|}{ 2) Ages 0-14 - Dallas 2018} \\
\hline Percent range & $\begin{array}{l}\text { New } \\
\text { Value }\end{array}$ \\
\hline $0.77-14.96$ & 1 \\
\hline $14.96-19.83$ & 2 \\
\hline $19.83-23.86$ & 3 \\
\hline $23.86-27.88$ & 4 \\
\hline $27.88-55$ & 5 \\
\hline
\end{tabular}

\begin{tabular}{|l|l|}
\hline \multicolumn{2}{|c|}{ 3) Ages 60+ - Dallas 2018} \\
\hline Percent range & $\begin{array}{l}\text { New } \\
\text { Value }\end{array}$ \\
\hline $1.72-12.19$ & 1 \\
\hline $12.19-17.75$ & 2 \\
\hline $17.75-24.62$ & 3 \\
\hline $24.62-36.40$ & 4 \\
\hline $36.40-85.48$ & 5 \\
\hline
\end{tabular}

\begin{tabular}{|l|l|}
\hline 4) Black - Dallas 2018 \\
\hline Percent range & $\begin{array}{l}\text { New } \\
\text { Value }\end{array}$ \\
\hline $0.00-14.06$ & 1 \\
\hline $14.06-32.42$ & 2 \\
\hline $32.42-51.56$ & 3 \\
\hline $51.56-72.26$ & 4 \\
\hline $72.26-100$ & 5 \\
\hline
\end{tabular}

\begin{tabular}{|l|l|}
\hline \multicolumn{2}{|l|}{ 5) Hispanic - Dallas 2018 } \\
\hline $\begin{array}{l}\text { Percent } \\
\text { range }\end{array}$ & $\begin{array}{l}\text { New } \\
\text { Value }\end{array}$ \\
\hline $1.65-17.01$ & 1 \\
\hline $17.01-33.15$ & 2 \\
\hline $33.15-52.36$ & 3 \\
\hline $52.36-71.57$ & 4 \\
\hline $71.57-100$ & 5 \\
\hline
\end{tabular}

\begin{tabular}{|l|l|}
\hline \multicolumn{2}{|l|}{$\begin{array}{l}\text { 6) Unemployed - Dallas } \\
\text { 2018 }\end{array}$} \\
\hline $\begin{array}{l}\text { Percent } \\
\text { range }\end{array}$ & $\begin{array}{l}\text { New } \\
\text { Value }\end{array}$ \\
\hline $0.00-3.94$ & 1 \\
\hline $3.94-7.89$ & 2 \\
\hline $7.89-13.07$ & 3 \\
\hline $13.07-22.44$ & 4 \\
\hline $22.44-63.14$ & 5 \\
\hline
\end{tabular}




\begin{tabular}{|l|l|}
\hline $\begin{array}{l}\text { 7) Rented homes- Dallas } \\
\text { 2018 }\end{array}$ \\
\hline Percent range & $\begin{array}{l}\text { New } \\
\text { Value }\end{array}$ \\
\hline $0.00-16.01$ & 1 \\
\hline $16.01-33.20$ & 2 \\
\hline $33.20-53.51$ & 3 \\
\hline $53.51-78.51$ & 4 \\
\hline $78.51-100$ & 5 \\
\hline
\end{tabular}

\begin{tabular}{|l|l|}
\hline \multicolumn{2}{|l|}{ 9) 0-14 - Phoenix 2018} \\
\hline Percent range & $\begin{array}{l}\text { New } \\
\text { Value }\end{array}$ \\
\hline $0.034-6.85$ & 1 \\
\hline $6.85-14.34$ & 2 \\
\hline $14.34-22.26$ & 3 \\
\hline $22.26-29.08$ & 4 \\
\hline $29.08-56.38$ & 5 \\
\hline
\end{tabular}

\begin{tabular}{|l|l|}
\hline \begin{tabular}{l} 
8) Income < \$25,000 - \\
Phoenix 2018 \\
\hline Percent range
\end{tabular} & $\begin{array}{l}\text { New } \\
\text { Value }\end{array}$ \\
\hline $0.07-11.06$ & 1 \\
\hline $11.06-19.24$ & 2 \\
\hline $19.24-28.70$ & 3 \\
\hline $28.70-40.97$ & 4 \\
\hline $40.97-65.52$ & 5 \\
\hline
\end{tabular}

10) Ages 60+ - Phoenix 2018

\begin{tabular}{|l|l|}
\hline $\begin{array}{l}\text { Percent } \\
\text { range }\end{array}$ & $\begin{array}{l}\text { New } \\
\text { Value }\end{array}$ \\
\hline $0.09-15.59$ & 1 \\
\hline $15.59-30.70$ & 2 \\
\hline $30.70-49.29$ & 3 \\
\hline $49.29-72.92$ & 4 \\
\hline $72.92-99.27$ & 5 \\
\hline
\end{tabular}

\begin{tabular}{|l|l|}
\hline \multicolumn{2}{|l|}{ 11) Black - Phoenix 2018} \\
\hline Percent range & $\begin{array}{l}\text { New } \\
\text { Value }\end{array}$ \\
\hline $0.00-4.96$ & 1 \\
\hline $4.96-11.59$ & 2 \\
\hline $11.59-19.63$ & 3 \\
\hline $19.63-30.28$ & 4 \\
\hline $30.28-60.56$ & 5 \\
\hline
\end{tabular}

\begin{tabular}{|l|l|}
\hline $\begin{array}{l}\text { 13) Unemployed - Phoenix } \\
\text { 2018 }\end{array}$ \\
\hline Percent range & $\begin{array}{l}\text { New } \\
\text { Value }\end{array}$ \\
\hline $0.00-3.94$ & 1 \\
\hline $3.90-8.98$ & 2 \\
\hline $8.98-15.23$ & 3 \\
\hline $15.23-25.39$ & 4 \\
\hline $25.39-100$ & 5 \\
\hline
\end{tabular}

\begin{tabular}{|l|l|}
\hline $\begin{array}{l}\text { 12) Hispanic - Phoenix } \\
\text { 2018 }\end{array}$ \\
\hline $\begin{array}{l}\text { Percent } \\
\text { range }\end{array}$ & $\begin{array}{l}\text { New } \\
\text { Value }\end{array}$ \\
\hline $0.20-16.02$ & 1 \\
\hline $16.02-35.53$ & 2 \\
\hline $35.53-54.67$ & 3 \\
\hline $54.678-72.33$ & 4 \\
\hline $72.33-94.42$ & 5 \\
\hline
\end{tabular}

\begin{tabular}{|l|l|}
\hline $\begin{array}{l}\text { 14) Rented } \\
\text { Phoenix 2018 }\end{array}$ \\
\hline $\begin{array}{l}\text { Percent } \\
\text { range }\end{array}$ & $\begin{array}{l}\text { New } \\
\text { Value }\end{array}$ \\
\hline $0.00-20.70$ & 1 \\
\hline $20.70-38.28$ & 2 \\
\hline $38.28-54.29$ & 3 \\
\hline $54.29-75.39$ & 4 \\
\hline $0.00-20.70$ & 5 \\
\hline
\end{tabular}

